\title{
Treatment with Anti-Gremlin 1 Antibody Ameliorates Chronic Hypoxia/SU5416-Induced Pulmonary Arterial Hypertension in Mice
}

Loredana Ciuclan, * KellyAnn Sheppard, ${ }^{\dagger}$ Liqun Dong, ${ }^{\ddagger}$ Daniel Sutton, ${ }^{*}$ Nicholas Duggan, * Martin Hussey, ${ }^{*}$ Jenny Simmons, * Nicholas W. Morrell, ${ }^{\S}$ Gabor Jarai, ${ }^{*}$ Matthew Edwards, ${ }^{*}$ Gerald DuBois, ${ }^{*}$ Matthew Thomas, ${ }^{*}$ Gino Van Heeke, ${ }^{*}$ and Karen England*

\begin{abstract}
From the Respiratory Disease Area,* Novartis Institutes for BioMedical Research, Horsham, West Sussex, United Kingdom; Developmental and Molecular Pathways, ${ }^{\dagger}$ Novartis Institutes for Biomedical Research, Inc., Cambridge, Massachusetts; the Genomics Institute of the Novartis Research Foundation, ${ }^{\ddagger}$ San Diego, California; and the Department of Medicine, ${ }^{\S}$ University of Cambridge School of Clinical Medicine, Addenbrooke’s and Papworth Hospitals,

Cambridge, United Kingdom
\end{abstract}

Accepted for publication

July 12, 2013.

Address correspondence to Matthew Thomas, Ph.D., Respiratory Disease Area, Novartis Institutes for BioMedical Research, Wimblehurst Rd., Horsham, West Sussex RH12 5AB, UK. E-mail: matthew.thomas@novartis. com.

\begin{abstract}
The expression of the bone morphogenetic protein antagonist, Gremlin 1, was recently shown to be increased in the lungs of pulmonary arterial hypertension patients, and in response to hypoxia. Gremlin 1 released from the vascular endothelium may inhibit endogenous bone morphogenetic protein signaling and contribute to the development of pulmonary arterial hypertension. Here, we investigate the impact of Gremlin 1 inhibition in disease after exposure to chronic hypoxia/SU5416 in mice. We investigated the effects of an anti-Gremlin 1 monoclonal antibody in the chronic hypoxia/SU5416 murine model of pulmonary arterial hypertension. Chronic hypoxic/SU5416 exposure of mice induced upregulation of Gremlin $1 \mathrm{mRNA}$ in lung and right ventricle tissue compared with normoxic controls. Prophylactic treatment with an anti-Gremlin 1 neutralizing $\mathrm{mAb}$ reduced the hypoxic/SU5416-dependent increase in pulmonary vascular remodeling and right ventricular hypertrophy. Importantly, therapeutic treatment with an anti-Gremlin 1 antibody also reduced pulmonary vascular remodeling and right ventricular hypertrophy indicating a role for Gremlin 1 in the progression of the disease. We conclude that Gremlin 1 plays a role in the development and progression of pulmonary arterial hypertension in the murine hypoxia/SU5416 model, and that Gremlin 1 is a potential therapeutic target for pulmonary arterial hypertension. (Am J Pathol 2013, 183: 1461-1473; http://dx.doi.org/10.1016/j.ajpath.2013.07.017)
\end{abstract}

Pulmonary arterial hypertension (PAH) is a life-threatening disease characterized by an imbalance of vasoactive factors and the progressive development of complex, obliterative vascular lesions of the precapillary pulmonary circulation. The consequent increased pulmonary vascular resistance leads to increased right ventricle (RV) afterload, fibrosis, ischemia, cardiac failure, and ultimately death. ${ }^{1-7}$ Current therapeutic approaches for the treatment of chronic pulmonary hypertension principally address vascular tone and thus provide symptomatic relief with little improvement in prognosis. ${ }^{1-3,}$

Although the fundamental molecular pathogenesis of this disease process remains poorly understood, a significant breakthrough was made with the identification of heterozygous loss-of-function mutations in the bone morphogenetic protein receptor type 2 (BMPR2) as the genetic abnormality underlying the rare heritable form of PAH. Furthermore, BMPR2 expression is markedly reduced in patients with idiopathic forms of the disease in the absence of BMPR2 mutations. ${ }^{6,9-13}$ These mutations cause attenuation of the normal cellular responses to bone morphogenetic proteins (BMPs) in the lung (eg, BMP2 and BMP4), resulting in

\footnotetext{
Supported by NIH grant 5 U42 RR006042, the Novartis Institutes for Biomedical Research, and Genomics Institute of the Novartis Research Foundation, and infrastructure support by the Cambridge NIHR Biomedical Research Centre (N.W.M.). N.W.M. received a research grant from Novartis

Disclosures: L.C., M.H., N.D., D.S., J.S., G.D.B., G.J., M.E,. M.T., G.V.H., K.S., L.D., and K.E. are employees of Novartis Institutes for BioMedical Research, UK/USA.
} 
Table 1 Antibodies used in this study

\begin{tabular}{|c|c|c|c|c|c|}
\hline Catalog No. & Clonality & Supplier & Antibody, epitope & Species & Dilution \\
\hline M0616 & Mouse-mono & Dako (Ely, UK) & $\mathrm{vWf}$ & $h, m, r$ & 1: $200(\mathrm{IHC})$ \\
\hline 3101 & Mouse-mono & Abcam (Cambridge, UK) & $\alpha-S M A$ & $h, m, r$ & 1: $200(\mathrm{IHC})$ \\
\hline AF956 & Goat-poly & R\&D Systems (Abingdon, UK) & Gremlin 1 & $h, m, r$ & 1: 200 (IHC) \\
\hline
\end{tabular}

h, human; IF, immunofluorescence; IHC, immunohistochemistry; m, mouse; r, rat; vWf, von Willebrand factor; WB, Western blot.

pulmonary hypertension. ${ }^{6,10,12,14}$ The BMPs bind to transmembrane receptors formed by dimerization of BMPR 1 and BMPR2, after which the intracellular kinase domain of BMPR2 phosphorylates its BMPR1 partner, thus initiating downstream signaling, including phosphorylation of Smad1/ 5/8. ${ }^{15}$ Subsequent studies reported that reduced BMP signaling was found in many nongenetic animal models of pulmonary hypertension, including hypoxic pulmonary hypertension. ${ }^{6,9,16,17}$ Using a microarray screening approach, Costello et al ${ }^{15,18}$ previously identified Gremlin 1 as one of a cluster of genes whose transcription was selectively increased in hypoxic pulmonary endothelial cells but was unchanged in the cardiac endothelial cells exposed to hypoxia. This gene was of particular interest, as it encodes a glycoprotein member of a large family of secreted BMP antagonists. ${ }^{15,19}$ Gremlin 1 binds with high affinity to BMP2 and BMP4, and inhibits their activity. Both BMP2 and 4 play a role in the homeostasis of normal circulation. ${ }^{19}$ Cahill et al $^{19}$ have recently demonstrated that Gremlin 1 haplodeficient mice were protected against hypoxia-induced increases in pulmonary vascular resistance. This raises the possibility that increased expression of Gremlin 1 contributes to decreased BMP signaling and PAH development, suggesting that antagonizing Gremlin 1 may offer a novel therapeutic opportunity. The murine chronic hypoxia model fails to reproduce the more complex vessel remodeling pathophysiology typical of pulmonary hypertension. Furthermore, prevention of mild pathology development does not equate with a potential therapeutic effect on established, more severe, pulmonary vascular lesions. Therefore, we sought to further investigate the involvement of Gremlin 1 in PAH patients and in the more severe mouse hypoxia/SU5416 preclinical model of PAH. Using a neutralizing antiGremlin 1 antibody, we investigated the impact of either preventing the development of complex PAH pathologies, or treating those established, in the chronic hypoxia/SU5416 murine model of PAH.

\section{Materials and Methods}

Reagents

Vascular endothelial growth factor receptor 2 (VEGFR2) inhibitor, SUGEN (SU5416; S8442), was purchased from
Sigma-Aldrich (Poole, UK). Recombinant human (rh) Gremlin 1, BMP2, BMP4, BMP7, and anti-Gremlin 1 antibody were purchased from R\&D Systems (Minneapolis, MN, and Abingdon, UK). Phospho-Smad1/5/8 antibodies were obtained from Cell Signaling Technology (Hitchin, UK). GAPDH antibody was obtained from Sigma-Aldrich. All primary antibodies used in this study are detailed in Table $1 . \mathrm{IR}^{680}$ and $\mathrm{IR}^{800}$ secondary antibodies were obtained from Li-Cor (Cambridge UK). Human microvascular endothelial cells (HMVECs) and pulmonary arterial smooth muscle cells (PASMCs) were obtained from Promocell (Heidelberg, Germany), and additional PASMCs were purchased from Lonza (Slough, UK). TaqMan probes (detailed in Table 2) were obtained from Applied Biosystems (Warrington, UK).

\section{Generation and Purification of Anti-Gremlin $1 \mathrm{mAbs}$}

A generation of anti-Gremlin 1 antibodies were initially attempted in hamsters. Attempts were unsuccessful, possibly due to high sequence identity between species; although hamster gremlin 1 sequence is unknown, mature mouse and rat gremlin 1 are $100 \%$ identical, with a $98.75 \%$ sequence homology with mature human gremlin. Therefore, we used Escherichia coli-expressed mature mouse Gremlin 1, which lacks glycosylation and is inactive in a luciferase reporter gene assay (RGA) for antibody generation. The E. coli-expressed mouse Gremlin protein was immunized in Bcl-2 transgenic mice (Jackson Laboratory, Bar Harbor, ME) using a repetitive immunization at multiple sites protocol. ${ }^{20}$ Lymphocytes from peripheral lymph nodes of immunized mice were fused with F0 myeloma cells (ATCC, Manassas, VA). Hybridoma

Table 2 List of Taqman Probes

\begin{tabular}{ll}
\hline Gene & Assay ID \\
\hline Mouse & \\
Id1 & Mm00775963_g1 \\
Pai1 & Mm00435860_m1 \\
Grem1 & Mm00488615_s1 \\
GAPDH & Mm99999915_g1 \\
Human & \\
BMPR2 & Hs00176148_m1 \\
Grem1 & Hs01879841_s1 \\
GAPDH & 4333764F \\
\hline
\end{tabular}


supernatants were screened against mammalian expressed, active mouse Gremlin 1 by ELISA. Positive clones were further subcloned to isolate mAbs. The mAbs were purified from serum-free conditioned media using Protein $G$ resin. Neutralizing mAbs were identified by RGA with active mouse gremlin. Cross-activity to mammalian-expressed, active human gremlin 1 (R\&D Systems, Abingdon, UK) was determined by ELISA, Biacore analysis, and RGA.

\section{Reporter Gene Assay}

HEK 293T cells were transfected with the BRE-Luc gene construct and stable clones were selected. Cells were seeded in a 96-well or 384-well assay plate at $5 \times 10^{5}$ cells $/ \mathrm{mL}$ and grown overnight at $37^{\circ} \mathrm{C}$ with $5 \% \mathrm{CO}_{2}$. Antibody and rhGremlin 1 were pre-incubated for 1 hour at room temperature. The $\mathrm{mAb}-$ Gremlin 1 mixtures were transferred to the assay plate containing cells, followed by the addition of rhBMP-4. The plates were continuously incubated for 20 hours. Luciferase activity was measured using Bright-Glo (Promega, Southampton, UK, and Madison, Wisconsin, US).

\section{In Vivo Experimental Design}

All animal procedures were conducted in accordance with the British Home Office regulations (Scientific Procedures) Act of 1986, United Kingdom. Animals were housed at $24^{\circ} \mathrm{C}$ in a 12 -hour light-dark cycle. Food and water were accessible ad libitum. Adult male and female C57/B16 mice $(n=10$ per group; $20 \pm 2.5 \mathrm{~g})$ were injected s.c. with SU5416, which was suspended in CMC $[0.5 \%$ (w/v) carboxymethylcellulose sodium, $0.9 \%(\mathrm{w} / \mathrm{v})$ sodium chloride, $0.4 \%(\mathrm{v} / \mathrm{v})$ polysorbate $80,0.9 \%(\mathrm{v} / \mathrm{v})$ benzyl alcohol in deionized water]. Control mice received only the vehicle. The prophylactic treatment protocol consisted of single weekly injection of SU5416 at $20 \mathrm{mg} / \mathrm{kg}$. The animals were exposed to chronic normobaric hypoxia $\left(\begin{array}{lll}10 \% & \mathrm{O}_{2}\end{array}\right)$ in a ventilated chamber for 21 days. Additional groups of animals received anti-Gremlin $1 \mathrm{mAb}$ (16E3-2-1) every 3 days $(10 \mathrm{mg} / \mathrm{kg}$ i.p., dissolved in PBS) or $\mathrm{mIgG} 1$ placebo. For the therapeutic setting, the mice were similarly kept in hypoxic conditions under SU5416 exposure for 3 weeks, with a further exposure for 3 weeks to only hypoxia during the antibody treatment. Normoxic $(\mathrm{Nx})$ controls were kept in room air. At the end of the treatment period, mice were anesthetized, and PAH pathology was assessed via echocardiography, hemodynamics, hypertrophy, histology, and molecular pathway profiling.

\section{Hemodynamic and RV Hypertrophy}

After treatments, right ventricular pressure (RVP) and right ventricular hypertrophy $(\mathrm{RVH})$ measurements were done as described. $^{21}$ Briefly, RVP was measured by a catheter inserted into the RV via the right jugular vein and mean systemic arterial pressure was recorded noninvasively using the CODA tail-cuff method. The RV was separated from the left ventricle plus the septum, and the weight ratio was determined to provide a measure for the RV hypertrophy. ${ }^{21,22}$ After hemodynamic measurements, peripheral venous blood samples were collected and lung tissue was processed for histological and molecular profiling.

\section{Echocardiographic Assessment}

Echocardiographic assessments were performed by ultrasound on 2\% isoflurane- anesthetized animals as previously described. ${ }^{21}$ Motion mode analysis was then used in short axis to measure RV wall thickness during diastole. The cardiac function was further analyzed by cardiac output. Analysis was performed using EchoPAC dimension software (GE Healthcare, Little Chalfont, Buckinghamshire, UK).

\section{Histology and IHC}

Lung tissue preparation, sectioning, staining, and vascular morphometry were done as described. ${ }^{21}$ Immunohistochemical (IHC) staining was performed with the BenchMark XT (Ventana Medical Systems Inc., Tucson, AZ). The degree of muscularization of small pulmonary vessels (10 to $100 \mu \mathrm{m}$ diameter) was assessed by double immunostaining the sections with an anti $\alpha$-smooth muscle actin antibody and anti-mouse von Willebrand factor (vWF) anitbody. Lung tissue sections $(3 \mu \mathrm{m})$ were stained with anti-Gremlin 1 and PSmad1/5/8 antibody. Antibody dilutions are detailed in Table 1 . The epithelium was excluded from analysis. Presented values are the mean of 10 fields taken from 10 lung sections per mouse $(n=10)$. All samples were scored simultaneously and blinded to the study conditions. The percentage of small vessels $(<100 \mu \mathrm{m})$ with occlusive intimal lesions was determined in airway perfusion-fixed lungs and stained with $\alpha$-smooth muscle actin and vWF antibody. An occlusive lesion was defined by an intimal layer occupying more than $50 \%$ of the lumen plus intima diameter. For Phospho-Smad1/5/8 analysis relative positivity (positive pixels divided by total of positive and negative pixels of lung section excluding epithelium) was analyzed using Imagescope software version 10.2.2.2319 (Aperio Technologies, Oxford, UK). Presented values were the mean of 10 fields (magnification $\times 40$ to $\times 63$ ) taken from 10 lung sections per mouse $(n=10)$. All samples were scored simultaneously and blinded to the study conditions.

\section{Protein Isolation and Immunoblotting}

Protein extraction from mouse lungs and Western blot analysis were performed as previously described. ${ }^{21}$ Blots were probed with rabbit anti-P Smad1/5/8 Ab, (Cell Signaling) and anti-Gremlin 1 antibody (R\&D Systems, Abingdon, UK), and anti-mouse GAPDH (Sigma-Aldrich) served as a loading control (Table 1). $\mathrm{IR}^{680}$ and $\mathrm{IR}^{800}$ secondary antibodies were obtained from Li-Cor. Densitometric analysis of 
protein bands was performed using the Li-Cor Odyssey scanner.

\section{Gene Expression Studies}

Total RNA was purified from crushed whole lung using the Qiagen RNeasy mini kit (Qiagen, Crawley, UK), according to the manufacturer's instructions, and $500 \mathrm{ng}$ of total RNA was transcribed to cDNA using QuantiTect Reverse Transcription (Qiagen). Quantitative real-time RT-PCR was performed with the Sequence Detection System ABI Prism
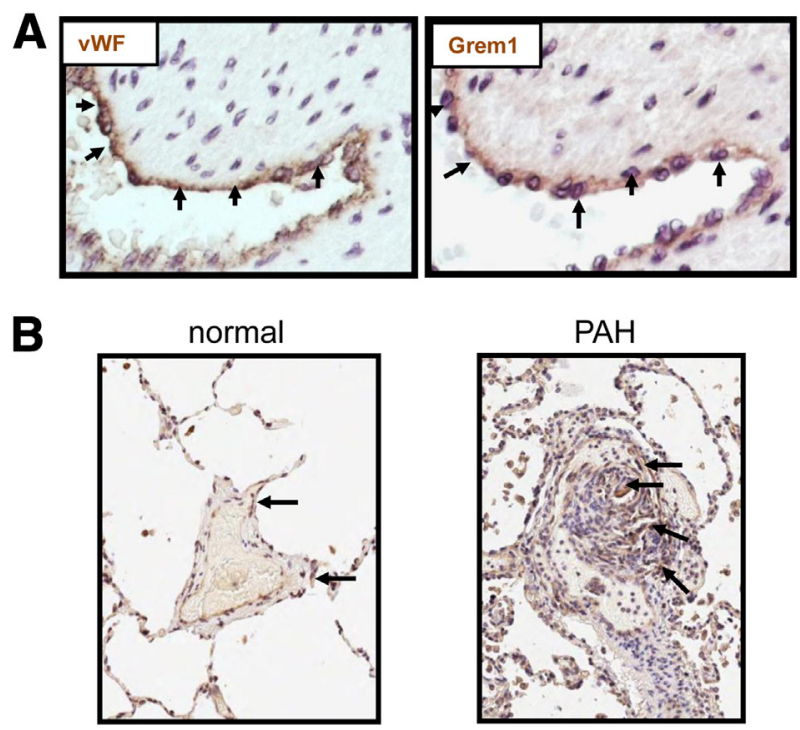

C

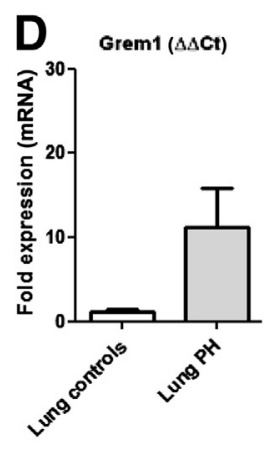

Figure 1 Gremlin 1 expression in pulmonary arterial hypertension (PAH) clinical samples. A: Representative of high magnification images of colocalized expression of VWF and Grem1 in human pulmonary vessel endothelium. Arrows indicate positive staining. B: Lung sections from biopsies of controls and PAH patients were stained with an anti-Gremlin 1 antibody. Gremlin 1 staining in PAH patient is associated with plexiform lesions. Arrows indicate positive Gremlin 1 staining. C: Bone morphogenetic protein receptor type 2 (BMPR2) and Gremlin 1 mRNA analysis in primary microvascular endothelial cells (HMVEC) and pulmonary arterial smooth muscle cells (PASMCs). Quantitative changes in gene expression were analyzed by RT-PCR normalized to GAPDH ( $\Delta \Delta$ Ct method). Data shown are representative from one donor of PASMCs and HMVECs. The experiments were performed in triplicate, with similar results observed in at least one other donor. D: Gremlin 1 mRNA expression in lungs from PAH patients. Secondary PAH lung samples were obtained from NDRI $(n=3)$. Quantitative changes in gene expression were analyzed by RT-PCR normalized to GAPDH ( $\Delta \Delta$ Ct method). Original magnification, $\times 20($ A and $\mathbf{B})$.
7700 (Applied Biosystems, Warrington, UK) using TaqMan Universal PCR Master Mix, No AmpErase UNG (Part No. 4324018) and the following gene expression assays: Greml, $B M P R 2$, and GAPDH. Samples from animals $(n=4)$ were analyzed in triplicate. Levels of gene expression in each sample were determined with the comparative $\mathrm{Ct}$ method. The gene expression assays details are listed in Table 2.

\section{Clinical Material for IHC Analysis}

The study was approved by the local research ethics committee, and all participants gave informed written consent. Patients with a confirmed diagnosis of idiopathic or heritable PAH were prospectively recruited at Papworth Hospital (Cambridge, UK) from 2001 to 2007. Idiopathic PAH was defined by mean pulmonary artery pressure of $>25 \mathrm{mmHg}$ at rest with a pulmonary capillary wedge pressure of $\leq 15 \mathrm{mmHg}$ with no underlying cause for PAH (Venice classification 1a). ${ }^{14}$ Control subjects were nondiseased sections from lung cancer cases. IHC was performed as described earlier.

\section{Gene Expression Analysis in Secondary PAH Patients}

We acknowledge the use of human tissues provided by the National Disease Research Interchange (NDR, Philadelphia, PA). Tissue was homogenized using GentleMax dissociator (Milltenyi, Surrey, UK) in RLT buffer from RNeasy Plus RNA extract kit (Qiagen), according to the manufacturer's instructions and as described earlier.

\section{Cell Culture of HMVECs and PASMCs}

HMVECs and PASMCs were obtained from Promocell; additional pulmonary arterial smooth muscle cells were purchased from Lonza. Cells were maintained as previously described. $^{23}$

\section{Immunofluorescent Analysis of Phospho-Smad1/5/8} and Analysis by High Content Screening

PASMCS were grown in 96-well Cell-Bind plates (Costar; Thermofisher Scientific, Basingstoke, UK) and treated for 1 hour with $80 \mathrm{ng} / \mathrm{mL}$ BMP4, $\pm 1 \mu \mathrm{g} / \mathrm{mL}$ rh Gremlin 1 for 1 hour, $\pm 10 \mu \mathrm{g} / \mathrm{mL}$ anti-Gremlin $1 \mathrm{mAb}$ 16E3-2-1. PASMCs were fixed and stained with an anti-phospho-smad1/5/8/Ab, and Hoechst dye. Quantification of phospho-smad1/5/8/and Hoechst staining in PASMCs was analyzed using ImageXpress (model IX5000) and MetaXpress software version 2.0.1.14 (both from Molecular Devices, Sunnyvale, CA).

\section{Statistical Analysis}

Statistical tests and graphs were performed using GraphPad (La Jolla, CA) Prism software version 5.0. $P<0.05$ was considered significant. Data presented are means \pm SEM for 5 to 10 animals per group. Significance of the in vivo 
A

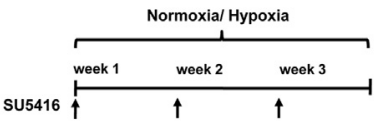

B

C
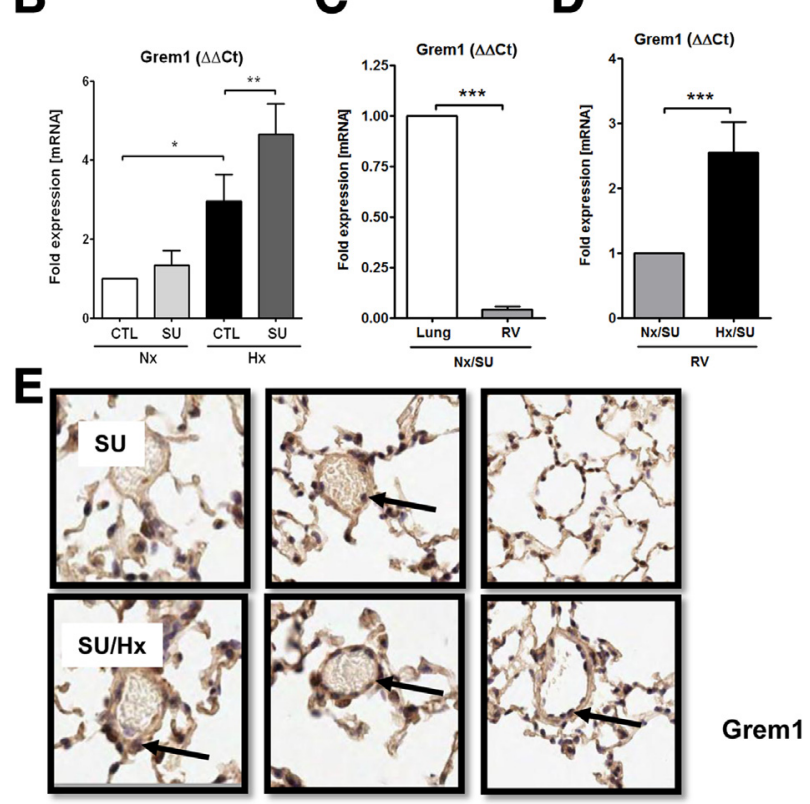

Figure 2 Gremlin 1 expression is increased in lungs and right ventricular (RV) tissue of mice exposed to chronic hypoxia/SU5416. A: Experimental setup to study the time course of SU5416 effects on pulmonary vessels; adult male C57/Bl6 mice were injected once weekly with SU5416 (20 mg/kg s.c.) or vehicle followed by exposure to chronic normobaric hypoxia $\left(10 \% 0_{2}\right)$ in a ventilated chamber for 3 weeks. The normoxic groups were kept in room air. B: Lung changes in mRNA expression of Gremlin 1 normalized to GAPDH in response to normoxia/hypoxia plus vehicle (CTL)/SU5416 (SU).C: Comparative analysis of Gremlin 1 mRNA expression in lung and RV. D: RV changes in mRNA Gremlin 1 normalized to GAPDH in response to normoxia/hypoxia plus vehicle. Quantitative changes in gene expression were analyzed by RT-PCR $(\Delta \Delta C \mathrm{Ct}$ method). Each bar shows means \pm SEM of four animals per group. E: Representative of high magnification images of IHC staining in mouse lung tissue for Gremlin 1. Arrows indicate positive staining in the endothelium. Statistical significances were determined using Student's $t$-test. ${ }^{*} P<0.05,{ }^{* *} P<0.01$, and ${ }^{* * *} P<0.001$. Original magnification, $\times 20(\mathrm{E})$.

response was determined using one-way analysis of variance with Tukey's multiple comparison test. Statistical significance for the in vitro data were analyzed by Student's $t$-test for unpaired data in two separated experiments.

\section{Results}

Gremlin 1 Expression Increases in the Plexiform Lesion of PAH Patients

To assess protein expression of Gremlin 1 in the human lung, we performed IHC studies. In PAH and control patients, Gremlin 1 was noted in endothelial cells of small pulmonary arteries and co-localized with expression of the endothelial marker vWF (Figure 1A) (pulmonary vascular lesions). In
PAH lungs, Gremlin protein expression was strong in plexiform lesions (Figure 1B and Supplemental Figure S1). There were no differences in the cellular expression pattern of Gremlin 1 in PAH endothelium compared to controls (Supplemental Table S1 and Supplemental Figure S2). Expression analysis confirmed that Gremlin $1 \mathrm{mRNA}$ is higher in HMVECs compared with PASMCs, again supporting a role for Gremlin 1 as an endothelial released factor (Figure 1C). In contrast, in PAH donors, BMPR2 expression is highest in PASMCs, suggesting that endothelial released Gremlin 1 may regulate BMP signaling in adjacent smooth muscle cell layers (Figure 1C). Interestingly, RT-PCR analysis of whole lung homogenate from secondary PAH patient samples also showed increased Gremlin 1 expression compared to control patients, although this did not reach statistical significance, probably due to the low patient number $(n=3)$ or vascular localization, which cannot be detected in a whole lung assay (Figure 1D).

Gremlin 1 Expression Increases in the Lungs and RV of Mice Exposed to Chronic Hypoxia/SU5416

Chronic hypoxia with the addition of a weekly injection of SU5416were used to model more severe, complex PAH pathologies than can be obtained using hypoxia alone, including medial wall hypertrophy and various degrees of neointimal thickening and occlusion ${ }^{21}$ (Figure 2A). Hemodynamic and RV hypertrophy analyses, as a measure of PAH pathology, showed that a combination of SU5416 with chronic hypoxia exacerbates $R V$ pressure rises and RV hypertrophy in response to hypoxia, as previously demonstrated. ${ }^{21} \mathrm{Nx}$ mice treated with SU5416 did not show elevated RVP or RVH when compared to vehicle-treated controls. ${ }^{21}$

Exposure to hypoxia was associated with a significant rise in lung Gremlin $1 \mathrm{mRNA}$ levels and SU5416 treatment further potentiated this effect (Figure 2B). Evaluation of housekeeping genes for quantitative mRNA analysis by TaqMan is shown in Supplemental Figure S3, and the induction of Gremlin mRNA by hypoxia alone is shown in Supplemental Figure S4. As PAH causes changes in cardiac physiology, we also looked at Gremlin 1 expression in the $\mathrm{RV}$ of mice exposed to hypoxia/SU5416. Gremlin $1 \mathrm{mRNA}$ expression in the RV was much lower than in the lung (Figure 2C); however, Gremlin 1 was significantly upregulated after hypoxia/SU5416 exposure (Figure 2D). IHC analysis of the mouse lungs shows a trend toward increased Gremlin 1 protein in hypoxia/SU5416-treated animals compared to control tissue. Similar to human PAH lung samples (Figure 1), Gremlin 1 expression is localized predominantly to the endothelial cells, with little expression in smooth muscle cell layer (Figure 2E).

\section{Characterization of an Anti-Gremlin mAb}

To investigate the role of Gremlin 1 in the in vivo model of hypoxia/SU5416, we developed an anti-Gremlin 1 
monoclonal antibody 16E3-2-1. The affinity of anti-Gremlin 1 $\mathrm{mAb}$ to Gremlin 1 was determined using the Biacore binding analysis. Briefly, mouse Gremlin 1 was immobilized on a CM5 chip followed by binding of 16E3-2-1 mAb in a concentration range of $1.6 \mathrm{nmol} / \mathrm{L}$ to $50 \mathrm{nmol} / \mathrm{L}$ to demonstrate an affinity/ $\mathrm{kDa}$ of $16 \mathrm{E} 3-2-1 \mathrm{mAb}$ to recombinant mouse Gremlin 1 of 5.6 $\times 10^{-10} \mathrm{~mol} / \mathrm{L}$ (Figure 3A). A BRE-Luciferase reporter gene assay demonstrated that the anti-Gremlin $1 \mathrm{mAb} 16 \mathrm{E} 3-2-1$ restored BMP-mediated signaling in a dose-dependent manner (with an $\mathrm{EC}_{50}$ of $295 \mathrm{nmol} / \mathrm{L}$ ) (Figure 3B). Human Gremlin has comparable activity in binding and RGA (data not shown). Immunofluorescence microscopy demonstrates that 16E3-2-1 $\mathrm{mAb}$ restored phospho-smad1/5/8 signaling in primary PASMCs treated with both BMP4 and rhGremlin 1, further demonstrating efficacious neutralizing activity of 16E3-2-1 (Figure 3, C and D).

\section{Prophylactic Effects of Anti-Gremlin 1 Antibody on PAH Pathology Is Observed in Hypoxia/SU5416 Mice}

To test the hypothesis that Gremlin 1 contributes to the development of pulmonary hypertension in vivo, we examined the changes in pulmonary vascular remodeling, hemodynamics, and heart function in response to sustained hypoxia/SU5416 exposure in mice in the presence of the Gremlin 1 neutralizing mAb 16E3-2-1. Animals $(n=10)$ were treated every 3 days with $10 \mathrm{mg} / \mathrm{kg}$ Gremlin 1 neutralizing mAb 16E3-2-1 or mouse IgG1 isotype control and were exposed to hypoxia for 21 days (Figure 4A). The dosing regime was based on the pharmacokinetic profile of 16E3-2-1 showing a 6-day half-life following i.p. dosing in mice (Supplemental Figure S5). Animals treated with 16E3-2-1 showed a modest increase in phosphorylation of Smad1/5/8 in the endothelium, suggesting that anti-Gremlin 1 $\mathrm{mAb}$ treatment increased BMP signaling within the vasculature (Figure 4, B and C).

Vessel muscularization is a key component of pulmonary hypertension and, given the potential for endothelialreleased Gremlin 1 to regulate BMP signaling in the smooth muscle cell layer within both the clinical samples and preclinical model, we investigated the impact of 16E3-2-1 on hypoxia/SU5416-induced vessel remodeling. We quantified the degree of muscularization in pulmonary arterioles of a diameter between 10 and $100 \mu \mathrm{m}$. Examination of lung $\alpha$ smooth muscle actin and vWF staining in Nx control lungs revealed that the majority of vessels were non-muscularized (Figure 4, D and E). In the hypoxia/SU5416-exposed
A
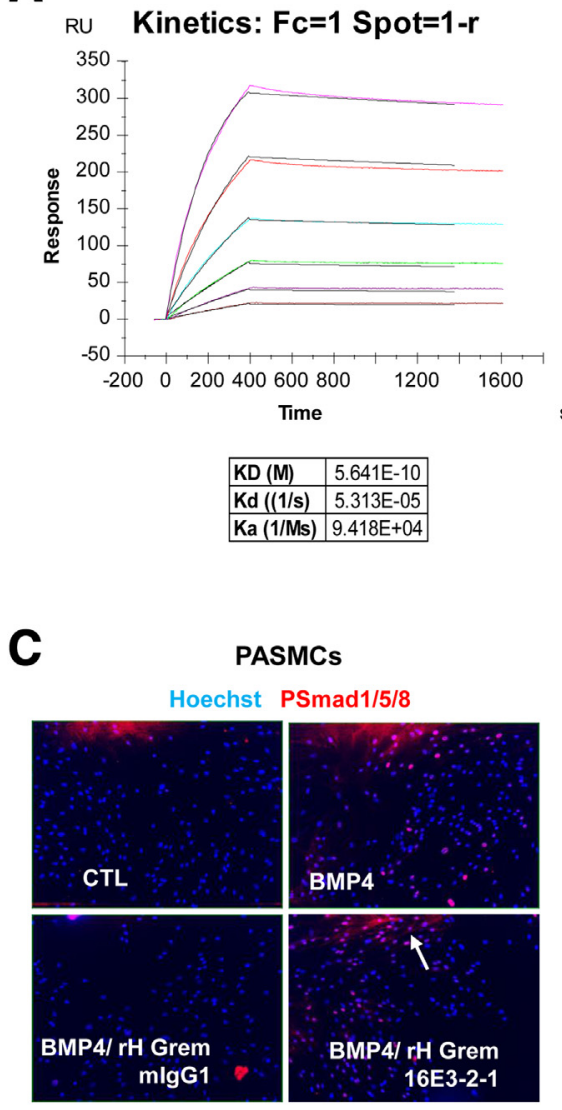

B

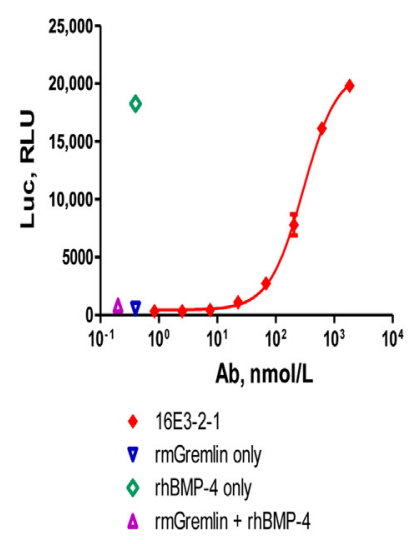

D

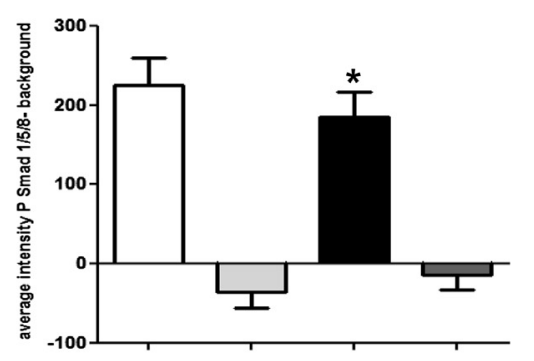

BMP4 (80ng/mL) + rhGrem 1 (1ug/mL) . mlgG control (100ug/mL) mlgG 16E3-2-1 (100ug/mL)
Figure 3 Characterization of an anti-Gremlin $1 \mathrm{mAb}$. A: Biacore analysis of 16E3-2-1 to recombinant mouse (rm) Gremlin 1. CM5 chip was immobilized with mouse $20 \mathrm{nmol} / \mathrm{L}$ mouse Gremlin 1 (R\&D Systems, Minneapolis, MN) followed by binding of $\mathrm{mAb} 16 \mathrm{E} 3-2-1$ in a range of concentration from 1.6 to $50 \mathrm{nmol} / \mathrm{L}$ (series of 1:2 dilution). B: RGA analysis of anti-Gremlin $1 \mathrm{mAb}$ on bone morphogenetic protein (BMP) signaling. HEK293 cells were stably transfected with the BMP reporter BRE-Luc (BMP response element fused to luciferase reporter) construct and BMP4 stimulation induced luciferase activity, which was reduced in cells treated with rmGremlin 1. Treatment with 16E3-2-1 mAb restores BMP-mediated increases in BRE-LUC activity in a dose- dependent manner in cells treated with both BMP4 and rmGremlin. C: Immunofluorescence analysis of pulmonary arterial smooth muscle cells (PASMCs) treated with BMP4 and recombinant human (rh)Gremlin. PASMCS were grown in 96-well cell bind plates and treated for 1 hour with $80 \mathrm{ng} / \mathrm{mL} \mathrm{BMP4,} \pm 1 \mu \mathrm{g} / \mathrm{mL}$ rhGremlin 1 for 1 hour, $\pm 10 \mu \mathrm{g} / \mathrm{mL}$ anti-Gremlin $1 \mathrm{mAb}$ 16E32-1. PASMCs were fixed and stained with an anti phospho-smad1/5/8/antibody and Hoechst dye. Phospho-smad1/5/8 nuclear translocation is seen as a pink nucleus. D: Quantification of phosphosmad1/5/8/and DAPI staining in PASMCS using high content screening. Each bar shows means \pm SEM of two independent experiments performed in triplicate. Similar results were seen with different PASMC donor cells (data not shown). Statistical significance was determined using Student's $t$-test. ${ }^{*} P<0.05$. Original magnification, $\times 10$ (C). 


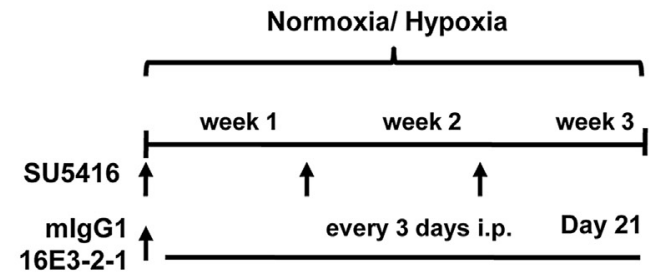

B

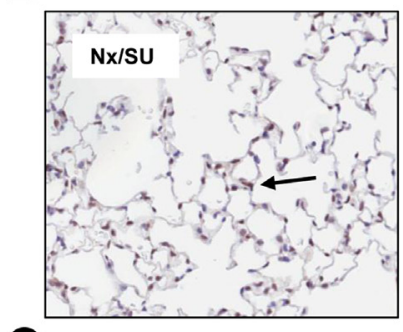

C

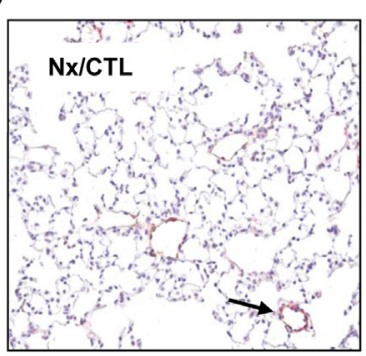

D

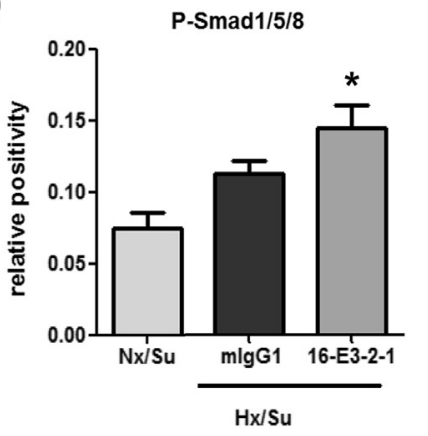

P-Smad1/5/8



SMA/ vWF

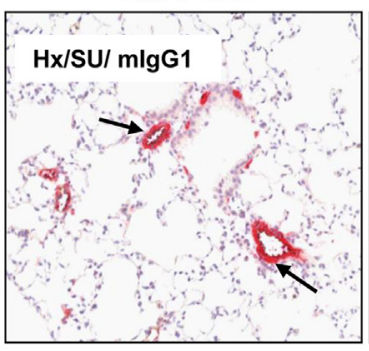

E

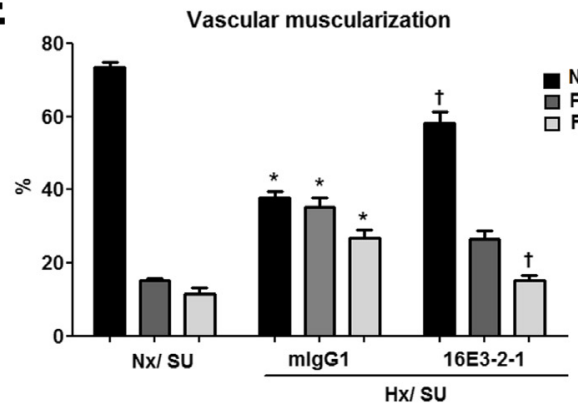

Figure 4 Prophylactic effects of anti-Gremlin 1 antibody on vascular remodeling and changes in bone morphogenetic protein (BMP) signaling pathway observed in hypoxia/SU5416 mice. A: AntiGremlin 1 mAb (16E3-2-1) and IgG control (mIgG1) effects on pulmonary arterial hypertension (PAH) development were determined in male C57/Bl6 mice injected every three days with vehicle (CTL) $(20 \mathrm{mg} / \mathrm{kg}$ i.p.) or SU5416 (SU) followed by exposure to chronic normobaric hypoxia $\left(\mathrm{Hx}, 10 \% \mathrm{O}_{2}\right)$ in a ventilated chamber or normoxia for 3 weeks. B and C: Representative images of IHC staining in lung tissue for phospho-Smad1/5/8 (B), and smooth muscle actin (SMA) (C); brown indicates positive expression (arrows). The vWF (brown) and $\alpha$-SMA (red) staining for identifying endothelium and vascular SMCs in small PA following 21 days treatment with 16E3-2-1 and mIgG1 under an $\mathrm{Nx} / \mathrm{Hx}$ environment. Representative images of the altered vessel phenotype in lung tissue (arrows). D: Quantification of the expression of phosphorylated Smad1/5/8 in the lung by IHC. The data plotted are the means \pm SEM of positive-stained tissue expressed as a percentage of the total parenchymal area. $P<0.05$ (Student's $t$-test) compared with control lung tissue area. $\mathbf{E}$ : The morphometric analysis for specific staining quantification of non $(\mathrm{N})$, partial $(\mathrm{P})$ or full $(\mathrm{F})$ vascular mascularization. ${ }^{*} P<0.05$ versus $\mathrm{Nx} / \mathrm{SU}$ group; ${ }^{\dagger} P<0.05$ versus $\mathrm{mIgG1} / \mathrm{Hx} / \mathrm{SU}$ group. Original magnification, $\times 10$ (B and $\mathbf{C})$. animals, a dramatic increase in fully-muscularized pulmonary arterioles occurred with a concomitant decrease in nonmuscularized vessels (Figure 4, D and E). Treatment with 16E3-2-1 resulted in a significant reduction in fullymuscularized arterioles with an associated increase of nonmuscularized vessels (Hx/SU/16E3-2-1 versus $\mathrm{Hx} / \mathrm{SU} / \mathrm{mIgG1}$; $P<0.05$ ) (Figure 4E).

Severe pulmonary vascular remodeling results in RV dysfunction, and treatments that modulate pulmonary vascular pathology should improve indices of cardiac function. In chronically hypoxic mice, severe PAH developed within 21 days, which was characterized by a significant increase in RVP as compared with $\mathrm{Nx}$ animals $(>45$ mmHg RVP; Hx/SU versus Nx/SU; $P<0.01$ ). Treatment with 16E3-2-1 significantly reduced the RVP in $\mathrm{Hx} / \mathrm{SU}$ mice (Hx/SU/16E3-2-1 versus $\mathrm{Hx} / \mathrm{SU} / \mathrm{mIgG1} ; P<0.05)$ (Figure 5A). In the hypoxia/SU5416 groups, significant RVH developed as a consequence of increased RVP. The ratio of $\mathrm{RV}$ weight to left ventricular plus septum weight increased from $0.20(\mathrm{Nx} / \mathrm{SU})$ to $0.35(\mathrm{Hx} / \mathrm{SU}$ group; $P<$ $0.05)$. Treatment with $16 \mathrm{E} 3-2-1$ caused a reduction of this ratio to $0.25(\mathrm{Hx} / \mathrm{SU} / 16 \mathrm{E} 3-2-1$ versus $\mathrm{Hx} / \mathrm{SU} / \mathrm{mIgG} 1 ; P<$ 0.05) (Figure 5B). Nx mice treated with SU5416 did not show elevated RVP or RVH when compared to vehicle-treated controls (Figure 5, A and B). Systemic blood pressure did not significantly change in any of the treatment groups (Figure 5C). Mice exposed to hypoxia/SU5416 showed an increase in the RV diastolic thickness (Hx/SU/16E3-2-1 versus $\mathrm{Hx} / \mathrm{SU} / \mathrm{mIgG1} ; P<0.05)$, which was significantly reduced by treatment with 16E3-2-1 (Figure 5D). In the 

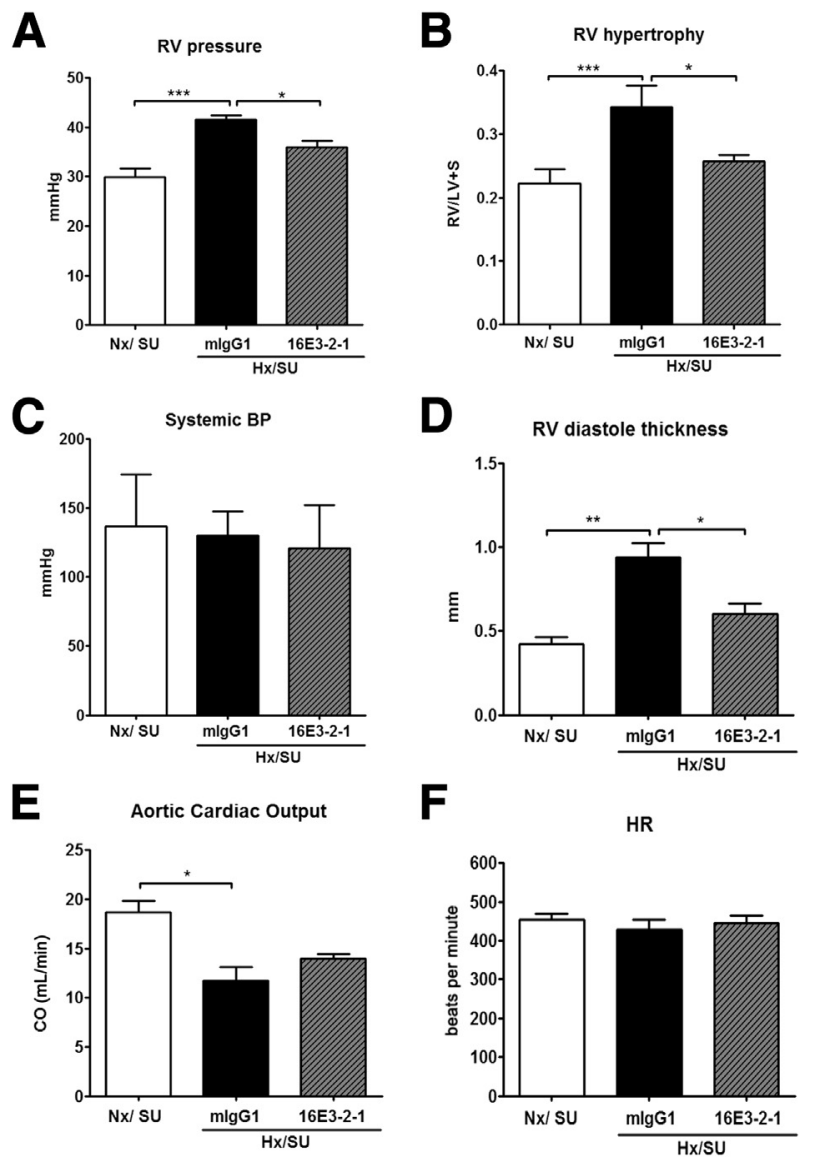

Figure 5 Prophylactic effects of anti-Gremlin 1 antibodies on hemodynamics and heart pathology observed in hypoxia/SU5416 (SU) mice. Effects of 16E3-2-1 and mIgG1 on development of RV systolic pressure (RVP; $\mathrm{mmHg}$ ) (A), RVH (Fulton index, the ratio of RV weight to left ventricular plus septum weight ratio) (B), systemic blood pressure (C), RV diastole thickness (D), aortic cardiac output (CO) $(\mathrm{mL} / \mathrm{min})(\mathbf{E})$, and heart rate during 21 days of $\mathrm{Hx}$ or $\mathrm{Nx}$ exposure (F). Data are means \pm SEM for 10 animals per group. Statistical differences are indicated by one-way analysis of variance analysis. ${ }^{*} P<0.05,{ }^{*} P<0.01$, and ${ }^{* * *} P<0.001$.

presence of SU5416, chronic hypoxia steadily decreased the cardiac output $(8 \mathrm{~mL} / \mathrm{min})$ as compared with control $\mathrm{Nx}$ (vehicle or SU5416) conditions (Figure 5E). Mice treated with 16E3-2-1 showed no significant recovery in cardiac output as compared to control treatment (Figure 5E). Heart rate did not significantly change between treatment groups (Figure 5F).

\section{Therapeutic Effects of Anti-Gremlin 1 Antibodies on} PAH Pathology Is Observed in Hypoxia/SU5416 Mice

Next, we investigated the therapeutic potential of antiGremlin $1 \mathrm{mAb}$ for the treatment of established PAH pathology after exposure to chronic hypoxia and SU5416. Mice were kept in hypoxic/SU5416 treatment conditions for 3 weeks, with a further exposure for 3 weeks to hypoxia only during the $\mathrm{mAb}$ treatment (Figure 6A). PhosphoSmad1/5/8 IHC analysis showed a small increase in vascular expression levels in 16E3-2-1-treated animals compared to control $\mathrm{mIgG1}$-treated mice (Figure 6, B and C). Western blot analysis also demonstrated similar increases in phospho smad1/5/8 levels in total lungs from 16E3-2-1-treated animals (Figure 6, D and E). The expression of Id1, a downstream marker of BMP pathway activity was also investigated. TaqMan analysis revealed a significant increase in Id1 mRNA expression in 16E3-21-treated hypoxic/SU5416 animals compared to controls (Figure 6F), suggesting an enhanced BMP signaling. Interestingly, the increase in Pail mRNA (gene induced by transforming growth factor- $\beta$ signaling pathway) after hypoxic/SU5416 exposure was slightly reduced, although it was not significantly reduced in 16E3-2-1-treated hypoxic mice $(P=0.09)$ (Figure $6 \mathrm{G})$. Together, these data suggest that treatment with anti-Gremlin $1 \mathrm{mAb}$ potentiates BMP signaling in this model, which may explain, at least in part, the mechanism of action.

The extent of vascular remodeling, a measure of PAH pathology, showed that by day 21 the majority of pulmonary arteries were FM, a change associated with a concomitant decrease in NM vessels. Similar to the findings when using the prophylactic regime, treatment with 16E3-2-1 after establishment of pathology resulted in a significant reduction in FM arteries after 42 days of hypoxia exposure. This correlated with a significant increase in the percentage of NM pulmonary arterioles (Figure 7A and B). Anti-Gremlin $1 \mathrm{mAb}$ had a significant effect on occlusive lesion formation with the number of fully occluded vessels being significantly reduced in 16E3-2-1-dosed mice (Figure 7, C and D). RVP rose from 25 to $45 \mathrm{mmHg}$ by day 21 of hypoxic/ SU6416 exposure, at which time point Gremlin 1 expression was inhibited for the following 3 weeks of hypoxic exposure alone. Treatment with 16E3-2-1 modestly attenuated the hypoxia/SU5416-induced increase in RVP compared to mIgG1 control mAb (Hx/SU/16E3-2-1 versus $\mathrm{Hx} / \mathrm{SU} /$ mIgG1; $P<0.05$ ) (Figure 8A). Right heart hypertrophy was significantly increased in hypoxic/SU5416/mIgG1 mice compared with the matched $\mathrm{Nx}$ groups, whereas it was significantly attenuated $(\mathrm{Hx} / \mathrm{SU} / 16 \mathrm{E} 3-2-1$ versus $\mathrm{Hx} / \mathrm{SU} /$ mIgG1; $P<0.05)$ in the animals treated with $16 \mathrm{E} 3-2-1$ RVH (Figure $8 \mathrm{~B}$ ). Mean systemic arterial pressure did not change in any of the treatment groups (Figure 8C). Echocardiographic analysis was used to look at the impacts of anti-Gremlin 1 therapy on right heart function. Mice exposed to chronic hypoxia and SU5416 showed an increase in the RV diastolic thickness at 42 days $(\mathrm{Hx} / \mathrm{SU} /$ mIgG1 versus SU5416; $P<0.05$ ), which was significantly reduced by treatment with 16E3-2-1 (Hx/SU/16E3-2-1 versus $\mathrm{Hx} / \mathrm{SU} / \mathrm{mIgG} 1 ; P<0.05$ ) (Figure $8 \mathrm{D}$ ). Chronic hypoxia/SU5416 exposure decreased the cardiac output $(8 \mathrm{~mL} / \mathrm{min})$ as compared with control $\mathrm{Nx} / \mathrm{SU}$ conditions (Figure 8E). Mouse subgroups therapeutically treated with 16E3-2-1 showed no significant recovery in cardiac output as compared to control treatment (Figure 8E). Heart rate did not significantly change between treatment groups (Figure 8F). 

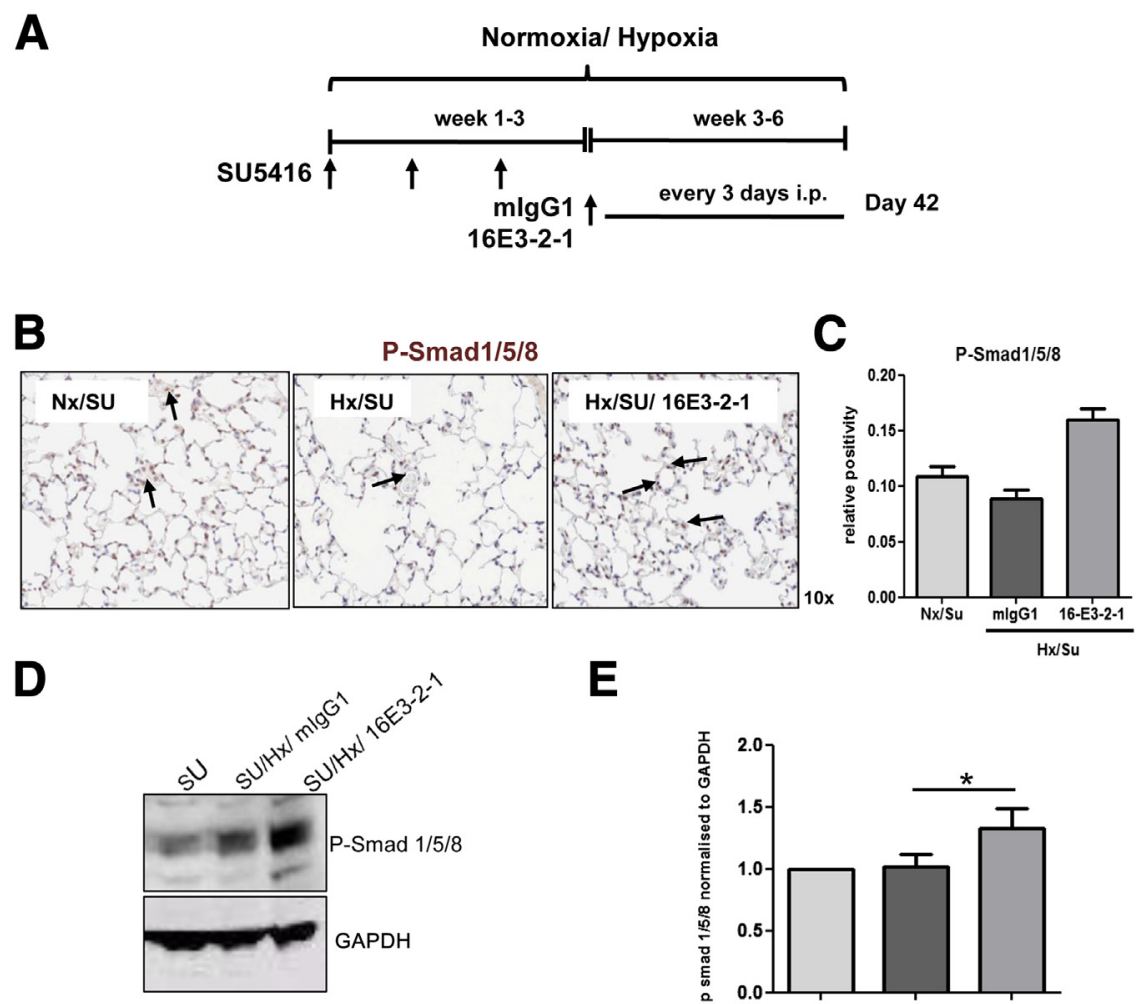

\section{E}

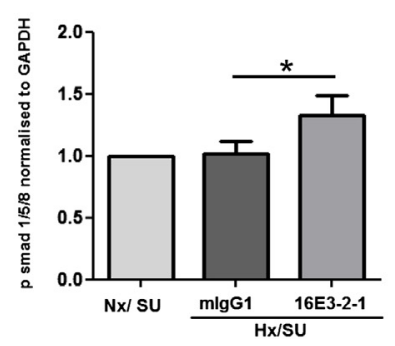

$\mathbf{F}$

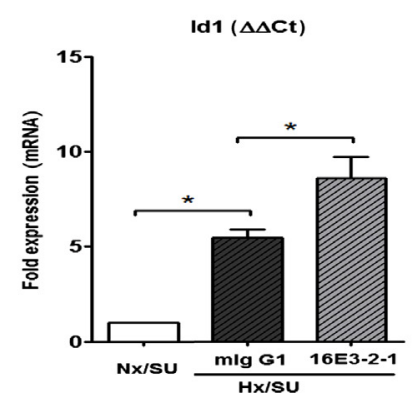

G

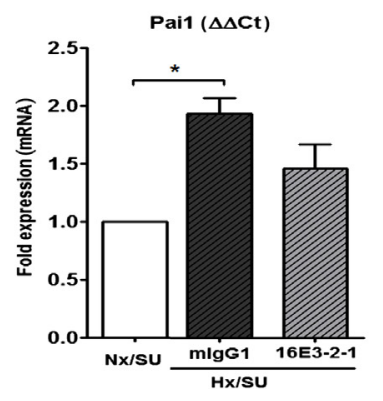

Figure 6 Therapeutic effects of anti-Gremlin 1 antibody on changes in bone morphogenetic protein (BMP) signaling pathway observed in hypoxia/SU5416 mice. A: For the therapeutic setting, the mice were kept in hypoxic conditions under SU4516 exposure for 3 weeks, with a further exposure for 3 weeks to only hyoxia $(\mathrm{Hx})$ during the 16E3-2-1 and mIgG1 treatment. Normoxia (Nx) controls were kept in room air. B: Representative images of IHC in lung tissue for phospho-Smad1/ 5/8, brown positive expression (arrows). C: Quantification of the expression of phosphorylated Smad1/5/8 in the lung by IHC $(n=10$ lungs). The data plotted are the means \pm SEM of positive-stained tissue expressed as a percentage of the total area excluding epithelium. D: Representative Western blots for expression of phosphoSmad1/5/8 and GAPDH from lungs exposed to $\mathrm{Nx} /$ $\mathrm{Hx}$ for 42 days and treated with 16E3-2-1 and mIgG1. E: Densitometry was performed using ImageJ software version $1.45 \mathrm{k}$ (NIH, Bethesda, MD; $n=9$ ) and normalized for GAPDH. Id1 (F) and Pai1 (G) mRNA expression from whole lung normalized to GAPDH. Quantitative changes in gene expression were analyzed by RT-PCR $(\Delta \Delta C \mathrm{Ct}$ method). Each bar shows means \pm SEM of four animals per group. ${ }^{*} P<0.05,{ }^{*} P P<0.01$, Student's $t$-test. Original magnification, $\times 10$ (B).

\section{Discussion}

There is robust clinical evidence of a role for decreased BMP signaling in the development of pulmonary hypertension. $^{24-26}$ Germline mutations of BMPR2 have been found in familial and sporadic forms of $\mathrm{PAH} .{ }^{27}$ Moreover, BMPR2 expression has also been reported to be decreased in both idiopathic and secondary forms of $\mathrm{PAH}^{25,26}$ Costello et $\mathrm{al}^{15}$ demonstrated an increase in the expression of the BMP antagonist Gremlin 1 in PAH patients at the mRNA level, suggesting another mechanism for decreased BMP signaling. In the present study, we provide further evidence for a role for Gremlin 1 in PAH pathology. We demonstrate that Gremlin 1 is expressed in human lung tissue of patients with $\mathrm{PAH}$, arising predominantly in pulmonary endothelial cells, which is associated with plexiform lesions. Although it is unclear whether Gremlin 1 expression is a driver of endothelial proliferation and lesion formation, or whether increased Gremlin 1 expression is simply associated with the increased number of endothelial cells in these lesions, there is potential for Gremlin 1 released from the endothelial cells to regulate BMP signaling in the adjacent smooth muscle cell layer. Despite the limitations, such as low number and large patient variability, there was clearly a trend toward increased Gremlin 1 mRNA expression in secondary PAH samples. These data support a role for involvement of Gremlin 1 in PAH pathology and a need to assess the potential role of antiGremlin 1 therapeutic approach in further preclinical and clinical studies. To further understand the Gremlin 1 mechanism of action in PAH pathology development, we investigated the Gremlin 1 expression in the murine hypoxia/SU5416 model of PAH. ${ }^{21}$ This model more closely recapitulates the pathological processes of clinical PAH, including complex vascular remodeling and cardiac indices that are not characteristic of alternative mouse models. ${ }^{21}$ 
A

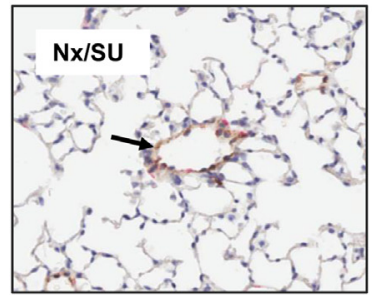

B
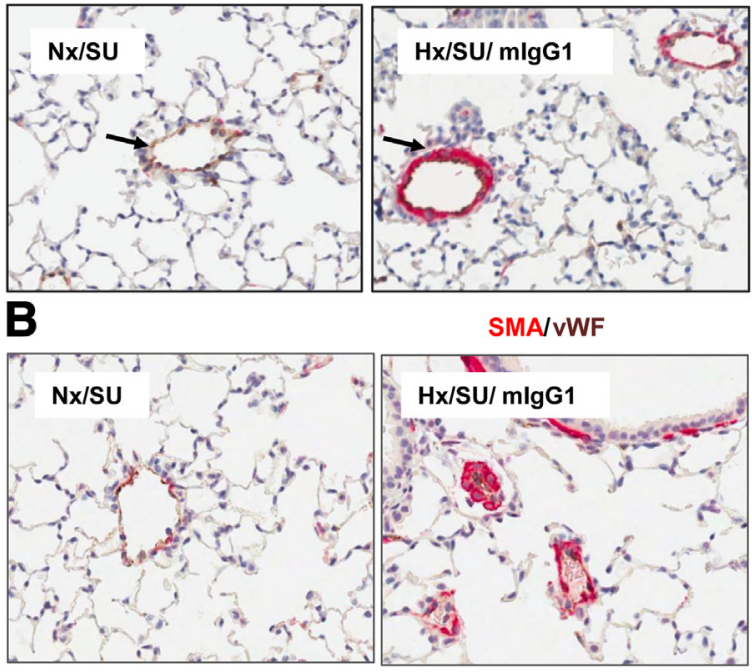

SMA/vWF

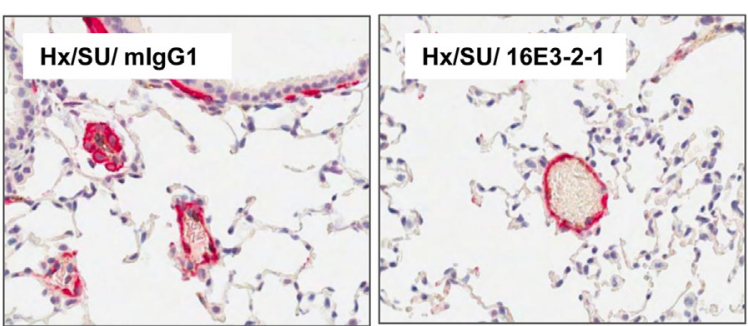

C

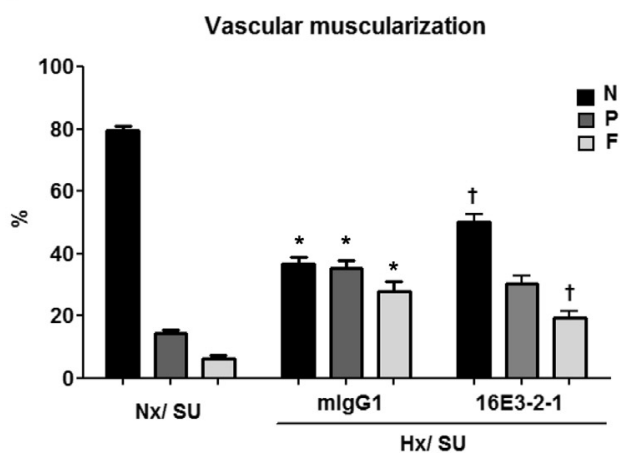

D

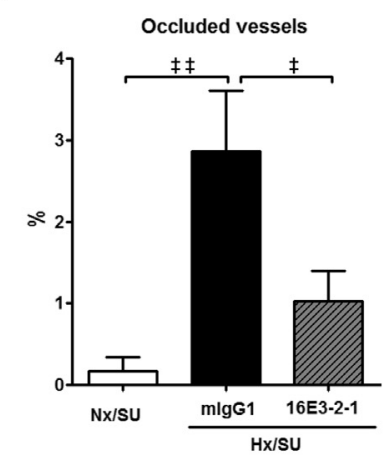

Figure 7 Therapeutic effects of anti-Gremlin 1 antibody on vascular remodeling observed in hypoxia/SU5416 mice. A: The degree of muscularization is demonstrated by VWF (brown) and $\alpha$-smooth muscle actin (SMA) (red) staining for identifying endothelium and vascular SMCs in small pulmonary arteries following 21 days treatment with $16 \mathrm{E} 3-2-1$ and $\mathrm{mIgG} 1$ during 42 days of $\mathrm{Nx} / \mathrm{Hx}$ environment. B: Effect of 16E3-2-1 on occlusive pulmonary lesions in $\mathrm{Hx} / \mathrm{SU} 5416 \mathrm{PAH}$. Representative image of an $\alpha$-SMA-stained occlusive pulmonary lesion in the $\mathrm{Hx} / \mathrm{SU} 5416 / \mathrm{mIgG1} \mathrm{PAH}$ (exposure, original magnification $\times 20$ ). C: Morphometric analysis for specific staining quantification of vascular muscularization. Statistical differences were determined by one-way analysis of variance. ${ }^{*} P<0.05$ $\mathrm{Hx} / \mathrm{SU} / \mathrm{mIgG} 1$ versus $\mathrm{Nx} / \mathrm{SU} ;{ }^{\dagger} P<0.05 \mathrm{Hx} / \mathrm{SU} /$ 16E3-2-1 versus $\mathrm{Hx} / \mathrm{SU} / \mathrm{mIgG1}$. D: Morphometric analysis for vessel occlusion. Results are expressed as means $\pm \operatorname{SEM}(n=10)$. Statistical differences were determined by analysis of variance. ${ }^{\ddagger} P<0.05$, $\ddagger \ddagger 0.01$.
Consistent with previous reports, we documented an early increase in whole lung Gremlin 1 mRNA expression after exposure to chronic hypoxia and SU5416. ${ }^{18}$ Distribution of Gremlin 1-positive cells in the model presented in this study as well as in clinical samples was consistent with data published by Costello et $\mathrm{al}^{18}$ in which mouse lungs exposed to chronic hypoxia showed Gremlin 1-positive cells were detected largely in the endothelium of small vessels.

However, similar to the patient samples, we did not see a large increase in Gremlin 1 protein expression within the lung on hypoxia/SU5416 induction of PAH. Although Gremlin 1 mRNA expression was very low within the RV, we did see an increase in Gremlin 1 levels in animals exposed to chronic hypoxia plus SU5416, suggesting that Gremlin 1 may also play a role within the cardiomyocytes PAH-related pathology. This novel finding warrants further investigation and supports our data that anti-Gremlin $1 \mathrm{mAb}$ treatment had a significant impact on cardiac readouts of pulmonary hypertension compared to a control antibody. Chronic hypoxia plus SU5416 only was performed within the experiment, however, as anticipated, the results for chronic hypoxia plus SU5416 and chronic hypoxia plus SU5416 plus mIgG1 were not different, and hence only the mIgG1 data are shown for clarity (data not shown).

The generation of a neutralizing anti-Gremlin $1 \mathrm{mAb}$ that restored BMP signaling in the presence of recombinant mouse or human Gremlin 1 in vitro allowed us to further investigate the role of Gremlin 1 in the development and progression of PAH in the hypoxia/SU5416 preclinical model. To test the hypothesis that Gremlin 1 is involved in the development of PAH in response to chronic hypoxia/SU5416 we examined the changes in pulmonary vascular remodeling, hemodynamics, and heart function using an anti-Gremlin $1 \mathrm{mAb}$. In the hypoxia/ SU5416-exposed mice, moderate-to-severe PAH developed within 21 days and anti-Gremlin 1 antibody treatment reduced the increase in RVP. Treatment did not affect systemic blood pressure, suggesting a lack of systemic vasodilatory effect. Consistent with similar studies, ${ }^{27}$ we previously showed that the combination of SU5416 and chronic hypoxia affected only the lung vasculature and not the vasculature of other organs. Based on these reports, we predict that any effects of the antiGremlin $1 \mathrm{mAb}$ are mediated via the lung tissue. Muscular cardiac hypertrophy was significantly decreased in 
A

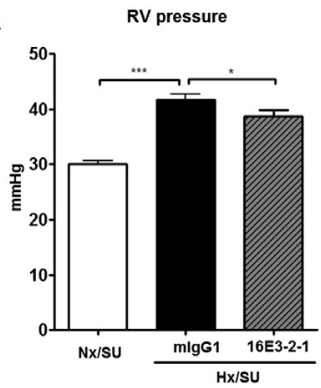

C

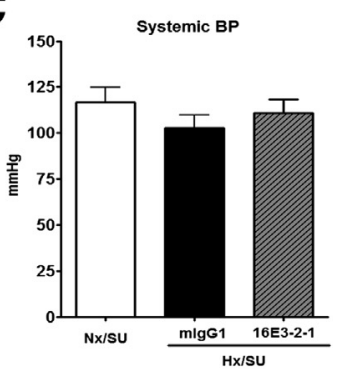

$\mathbf{E}$

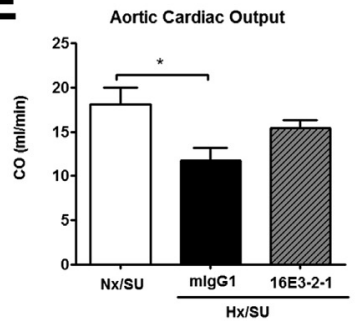

B

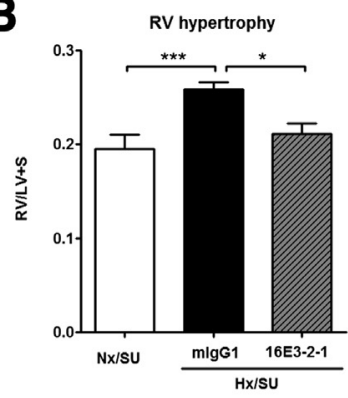

D

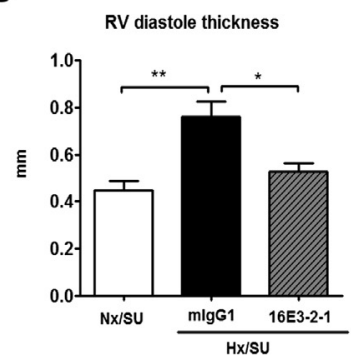

$\mathbf{F}$

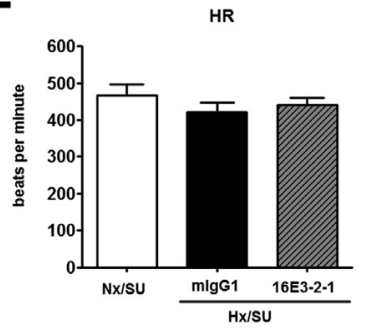

Figure 8 Therapeutic effects of anti-Grem1 antibodies on hemodynamics and heart pathology observed in hypoxia/SU5416 (SU) mice. Effects of therapeutic administration of 16E3-2-1 and mIgG1 on development of: RV systolic pressure (RVP; $\mathrm{mmHg}$ ) (A), RVH (Fulton index, the ratio of RV weight to left ventricular plus septum weight ratio (B), systemic blood pressure (C), RV diastole thickness (D), aortic cardiac output (CO) ( $\mathrm{mL} / \mathrm{min})$ $(\mathrm{E})$, and heart rate during 42 days of hypoxia $(\mathrm{Hx})$ or normoxia $(\mathrm{Nx})$ exposure (F). Data are means \pm SEM for 10 animals per group. Statistical differences are indicated by analysis of variance analysis. ${ }^{*} P<0.05,{ }^{*} P<$ $0.01,{ }^{* * * P}<0.001$

hypoxic mice treated with anti-Gremlin $1 \mathrm{mAb}$. Similarly, hypoxic/SU5416 animals treated with the antiGremlin $1 \mathrm{mAb}$ showed a reduction in $\mathrm{RV}$ diastole thickness, although there was no impact on cardiac output implying less impact on the heart failure process as a measure of end stage disease in the model. We also investigated the impact of anti-Gremlin 1 treatment on vessel pathology, looking at vessel muscularization. Histological analysis demonstrated that the percentage of partial and fully muscularized arterioles in hypoxia/ SU5416 mice were greater than those in the control group and nonmuscularized vessels were dramatically reduced, as previously described. ${ }^{21}$ Treatment with anti-Gremlin 1 $\mathrm{mAb}$ resulted in a significant reduction in fully muscularized vessels, demonstrating a role for Gremlin 1 in preventing vascular remodeling in this preclinical model. Similarly, data from Cahill et al $^{19}$ demonstrated that haplodeficiency of Gremlin1 augmented BMP signaling in the hypoxic mouse lung and reduced pulmonary vascular resistance by attenuating vascular remodeling.

Despite only a modest increase in phosphorylated Smad1/ $5 / 8$ after anti-Gremlin $1 \mathrm{mAb}$ treatment, inhibition of Gremlin1 in a prophylactic regime had a significant impact on disease development, as demonstrated by reduced vascular remodeling and RVH hypertrophy. Given the expression of Gremlin 1 within the endothelium, and the proposed role of endothelial damage in the development of PAH, we investigated the therapeutic potential of antiGremlin 1 antibodies for the treatment of established PAH pathology after exposure to chronic hypoxia and SU5416. Similar to prophylactic treatment, we demonstrate a positive effect of anti-Gremlin $1 \mathrm{mAb}$ treatment in reduction of $\mathrm{RV}$ pressure, although this effect was less pronounced compared to prophylactic treatment. However, treatment with antiGremlin $1 \mathrm{mAb}$ demonstrated a more robust impact on increased RV hypertrophy and RV diastole thickness after hypoxic/SU5416 insult.

To understand the implications of anti-Gremlin 1 treatment on lung pathology better, we evaluated vessel muscularization and occlusion, two key drivers in pulmonary hypertension. Therapeutic dosing of anti-Gremlin $1 \mathrm{mAb}$ had a significant impact on vessel remodeling, reducing the number of fully muscularized vessels, and increasing the number of nonmuscularized vessels, compared to hypoxia/ SU5416-exposed animals. One possible mechanism of action is that the release of Gremlin 1 from the endothelial cell layer may modulate BMP signaling in the smooth muscle cell layer with immediate effects on proliferation and extracellular matrix depositions. Decreased BMP signaling in pulmonary hypertension, due to decreased BMPR2 levels and/or locally high levels of Gremlin 1 could result in increased smooth muscle cell proliferation, potentially through increased transforming growth factor- $\beta$ signaling responses. $^{22}$ Although the effects of the anti-Gremlin $\mathrm{mAb}$ on BMP and transforming growth factor- $\beta$ signaling were subtle in the whole lung, there may be significant local regulation, which impacts BMP signaling and results in changes to cell behavior and remodeling ${ }^{28}$.

Analysis of vascular occlusion in the PAH mouse lungs demonstrated a significant reduction in vessel obstruction after therapeutic dosing of the anti-Gremlin $1 \mathrm{mAb}$. Once again, this may be mediated by localized changes in BMP signaling, resulting in decreased vascular proliferation, and vessel occlusion, although other mechanisms may contribute to the observed efficacy of anti-Gremlin $1 \mathrm{mAb}$ treatment. Interestingly, Gremlin 1 has recently been reported to signal through $\mathrm{VEGFR}^{2,28}$ a pro-angiogenic factor that could drive endothelial cell proliferation and vessel occlusion. Although we failed to demonstrate evidence for increased VEGFR2 phosphorylation in microvascular endothelial cells in response to Gremlin 1 (Supplemental Figure S6), this remains a potential mechanism of action for Gremlin 1 in endothelial cells. Although of interest for PAH this potential mechanism of action for Gremlin 1 may 
be difficult to delineate in this particular model, which involves exposure to SU5416, a VEGFR2 inhibitor, and hence alternative models, such as the rat monocrotaline PAH model may be required. Given the dysregulation of the BMP signaling pathway in the development of PAH, it is likely that an anti-Gremlin 1 therapy may exert therapeutic benefit through restoration of BMP signaling. Gremlin 1-mediated modulation of BMP signaling has also been implicated in other diseases, including glaucoma, diabetic nephropathy, and pulmonary fibrosis, ${ }^{29-34}$ and hence an anti-Gremlin 1 treatment approach may be considered of interest for treatment of these diseases. Furthermore, Gremlin 1 overexpression has also been associated with pathologies in which alternative mechanisms of action, independent of BMP regulation, may be important. Kim et $\mathrm{al}^{35}$ describe a BMP independent role for Gremlin 1 in tumor cell proliferation, and they also suggest that the interaction of Gremlin 1 with cancer cells is independent of both BMP and VEGFR2. As mentioned earlier, Gremlin 1 has also been demonstrated to be a VEGFR2 agonist ${ }^{29}$ which offers another potential mechanism of action for Gremlin 1 in pathology development.

\section{Conclusion}

Our data supports the benefit of an anti-Gremlin 1 therapy for pulmonary hypertension, particularly in patients with impaired BMP signaling. We demonstrate a positive role for Gremlin 1 in preventing the development of pulmonary hypertension and vascular remodeling in a robust preclinical murine model of PAH. Importantly, we have shown that therapeutic intervention to inhibit Gremlin 1 can attenuate PAH pathology, in particular cardiac hypertrophy, vessel remodeling, and occlusion, suggesting the potential for an anti-Gremlin 1 approach for the treatment of PAH.

\section{Acknowledgments}

We thank the excellent technical assistance of the members of the in vivo team (Olivier Bonneau and David Rowlands), Laboratory Animal Services (Andy Nicholls, Barrie Sandells, Dave Bateman, Michael George, and Sarah Lane), the members of the Histology Department led by Dr. Paul Whittaker, and Lilin Li (Global Novartis Foundation) for performing hybridoma fusions, ELISAs, and RGA screens.

L.C., M.H., N.D., M.T., and K.E. designed and performed in vivo experiments, analyzed the data, and contributed to the writing of the manuscript; L.D. and K.A.S. developed and analyzed anti-Gremlin $1 \mathrm{mAb}$ in vitro; J.S. and K.E. performed biochemical analysis of the in vivo samples; D.S. performed IHC studies; N.M. provided clinical samples and contributed to the final draft of the manuscript; G.D., G.J., M.E., and G.V.H. provided intellectual input; and M.T. and K.E. provided project supervision.

\section{Supplemental Data}

Supplemental material for this article can be found at http://dx.doi.org/10.1016/j.ajpath.2013.07.017.

\section{References}

1. Abe K, Toba M, Alzoubi A, Ito M, Fagan KA, Cool CD, Voelkel NF, Oka M: Formation of plexiform lesions in experimental severe pulmonary arterial hypertension. Circulation 2010, 121:2747-2754

2. Humbert M, Morrell NW, Archer SL, Stenmark KR, MacLean MR, Lang IM, Christman BW, Weir EK, Eickelberg O, Voelkel NF, Rabinovitch M: Cellular and molecular pathobiology of pulmonary arterial hypertension. J Am Coll Cardiol 2004, 43:13S-24S

3. Rabinovitch M: Pathobiology of pulmonary hypertension. Ann Rev Pathol 2007, 2:369-399

4. Stenmark KR, McMurtry IF: Vascular remodeling versus vasoconstriction in chronic hypoxic pulmonary hypertension: a time for reappraisal? Circ Res 2005, 97:95-98

5. Stenmark KR, Fagan KA, Frid MG: Hypoxia-induced pulmonary vascular remodeling: cellular and molecular mechanisms. Circ Res 2006, 99:675-691

6. Tuder RM, Cool DC, Yeager M, Taraseviciene-Stewart L, Bull TM, Voelkel NF: The pathobiology of pulmonary hypertension. Endothelium. Clin Chest Med 2001, 22:405-418

7. Tuder RM, Abman SH, Braun T, Capron F, Stevens T, Thistlethwaite PA, Haworth SG: Development and pathology of pulmonary hypertension. J Am Coll Cardiol 2009, 54:S3-S9

8. Ghofrani HA, Distler O, Gerhardt F, Gorenflo M, Grunig E, Haefeli WE, Held M, Hoeper MM, Kahler CM, Kaemmerer H, Klose H, Köllner V, Kopp B, Mebus S, Meyer A, Miera O, Pittrow D, Riemekasten G, Rosenkranz S, Schranz D, Voswinckel R, Olschewski H: Treatment of pulmonary arterial hypertension (PAH): updated Recommendations of the Cologne Consensus Conference 2011. Int J Cardiol 2011, 154(Suppl 1):S20-S33

9. Moller T, Leren TP, Eiklid KL, Holmstrom H, Fredriksen PM, Thaulow E: A novel BMPR2 gene mutation associated with exerciseinduced pulmonary hypertension in septal defects. Scand Cardiovasc J 2010, 44:331-336

10. Morty RE, Nejman B, Kwapiszewska G, Hecker M, Zakrzewicz A, Kouri FM, Peters DM, Dumitrascu R, Seeger W, Knaus P, Schermuly RT, Eickelberg O: Dysregulated bone morphogenetic protein signaling in monocrotaline-induced pulmonary arterial hypertension. Arterioscler Thromb Vasc Biol 2007, 27:1072-1078

11. Rosenzweig EB, Morse JH, Knowles JA, Chada KK, Khan AM, Roberts KE, McElroy JJ, Juskiw NK, Mallory NC, Rich S, Diamond B, Barst RJ: Clinical implications of determining BMPR2 mutation status in a large cohort of children and adults with pulmonary arterial hypertension. J Heart Lung Transplant 2008, 27:668-674

12. Talati M, West J, Blackwell TR, Loyd JE, Meyrick B: BMPR2 mutation alters the lung macrophage endothelin-1 cascade in a mouse model and patients with heritable pulmonary artery hypertension. Am J Physiol Lung Cell Mol Physiol 2010, 299:L363-L373

13. West J, Tada Y, Fagan KA, Steudel W, Fouty BW, Harral JW, Miller M, Ozimek J, Tuder RM, Rodman DM: Suppression of type II bone morphogenic protein receptor in vascular smooth muscle induces pulmonary arterial hypertension in transgenic mice. Chest 2005, $128(6$ Suppl):553S

14. West J, Cogan J, Geraci M, Robinson L, Newman J, Phillips JA, Lane K, Meyrick B, Loyd J: Gene expression in BMPR2 mutation carriers with and without evidence of Pulmonary Arterial Hypertension suggests pathways relevant to disease penetrance. BMC Med Genomics 2008, 1:45

15. Costello CM, Cahill E, Martin F, Gaine S, McLoughlin P: Role of gremlin in the lung development and disease. Am J Resp Cell Mol Biol 2010, 42:517-523 
16. Long L, Crosby A, Yang XD, Southwood M, Upton PD, Kim DK, Morrell NW: Altered bone morphogenetic protein and transforming growth factor-beta signaling in rat models of pulmonary hypertension potential for activin receptor-like kinase-5 inhibition in prevention and progression of disease. Circulation 2009, 119:566-576

17. Tuder RM, Yeager ME, Geraci M, Golpon HA, Voelkel NF: Severe pulmonary hypertension after the discovery of the familial primary pulmonary hypertension gene. Eur Respir J 2001, 17:1065-1069

18. Costello CM, Howell K, Cahill E, McBryan J, Konigshoff M, Eickelberg O, Gaine S, Martin F, McLoughlin P: Lung-selective gene responses to alveolar hypoxia: potential role for the bone morphogenetic antagonist gremlin in pulmonary hypertension. Am J Physiol Lung Cell Mol Physiol 2008, 295:L272-L284

19. Cahill E, Costello CM, Rowan SC, Harkin S, Howell K, Leonard MO, Southwood M, Cummins EP, Fitzpatrick SF, Taylor CT, Morrell NW, Martin F, McLoughlin P: Gremlin plays a key role in the pathogenesis of pulmonary hypertension. Circulation 2012, 125:920-930

20. Kilpatrick KE, Wring SA, Walker DH, Macklin MD, Payne JA, Su JL, Champion BR, Caterson B, McIntyre GD: Rapid development of affinity matured monoclonal antibodies using RIMMS. Hybridoma 1997, 16:381-389

21. Ciuclan L, Bonneau O, Hussey M, Duggan N, Holmes AM, Good R, Stringer R, Jones P, Morrell NW, Jarai G, Walker C, Westwick J, Thomas M: A novel murine model of severe pulmonary arterial hypertension. Am J Respir Crit Care Med 2011, 184:1171-1182

22. Thomas M, Docx C, Holmes AM, Beach S, Duggan N, England K, Leblanc C, Lebret C, Schindler F, Raza F, Walker C, Crosby A, Davies RJ, Morrell NW, Budd DC: Activin-like kinase 5 (ALK5) mediates abnormal proliferation of vascular smooth muscle cells from patients with familial pulmonary arterial hypertension and is involved in the progression of experimental pulmonary arterial hypertension induced by monocrotaline. Am J Pathol 2009, 174:380-389

23. Dooley S, Hamzavi J, Ciuclan L, Godoy P, Ilkavets I, Ehnert S, Ueberham E, Gebhardt R, Kanzler S, Geier A, Breitkopf K, Weng H, Mertens PR: Hepatocyte-specific Smad7 expression attenuates TGFbeta-mediated fibrogenesis and protects against liver damage. Gastroenterology 2008, 135:642-659

24. Burton VJ, Ciuclan LI, Holmes AM, Rodman DM, Walker C, Budd DC: Bone morphogenetic protein receptor-II regulates pulmonary artery endothelial cell barrier function. Blood 2011, 118: $4750-4758$

25. Machado RD, James V, Southwood M, Harrison RE, Atkinson C, Stewart S, Morrell NW, Trembath RC, Aldred MA: Investigation of second genetic hits at the BMPR2 locus as a modulator of disease progression in familial pulmonary arterial hypertension. Circulation 2005, 111:607-613

26. Morrell NW, Adnot S, Archer SL, Dupuis J, Jones PL, MacLean MR, McMurtry IF, Stenmark KR, Thistlethwaite PA, Weissmann N, Yuan JX, Weir EK: Cellular and molecular basis of pulmonary arterial hypertension. J Am Coll Cardiol 2009, 54 (Suppl 1):S20-S31

27. Sakao S, Tatsumi K: The effects of antiangiogenic compound SU5416 in a rat model of pulmonary arterial hypertension. Respiration 2010, $81: 253-261$

28. Davies RJ, Holmes AM, Deighton J, Long L, Yang XD, Barker L, Walker C, Budd DC, Upton PD, Morrell NW: BMP type II receptor deficiency confers resistance to growth inhibition by TGF-beta in pulmonary artery smooth muscle cells: role of proinflammatory cytokines. Am J Physiol Lung Cell Mol Physiol 2012, 302: L604-L615

29. Mitola S, Ravelli C, Moroni E, Salvi V, Leali D, Ballmer-Hofer K, Zammataro L, Presta M: Gremlin is a novel agonist of the major proangiogenic receptor VEGFR2. Blood 2010, 116:3677-3680

30. Sethi A, Jain A, Zode GS, Wordinger RJ, Clark AF: Role of TGF beta/Smad signaling in gremlin induction of human trabecular meshwork extracellular matrix proteins. Invest Opthamol Vis Sci 2011, 52: $5251-5259$

31. Farkas L, Farkas D, Gauldie J, Warburton D, Shi W, Kolb M: Transient overexpression of gremlin results in epithelial activation and reversible fibrosis in rat lungs. Am J Resp Cell Mol Biol 2011, 44: 870-878

32. Zhang QX, Shi YH, Wada J, Malakauskas SM, Liu MD, Ren YZ, Du CY, Duan HJ, Li YM, Li Y, Zhang YL: The in vivo delivery of gremlin siRNA plasmid reveals therapeutic potential against diabetic nephropathy by recovering bone morphogenetic protein-7. PLOS One 2010, 5:e11709

33. Zode GS, Clark AF, Wordinger RJ: Bone morphogenetic protein 4 inhibits TGF-beta 2 stimulation of extracellular matrix proteins in optic nerve head cells: role of gremlin in ECM modulation. Glia 2009, 57: 755-766

34. Myllarniemi M, Lindholm P, Ryynanen MJ, Klimet CR, Salmenkivi K, Keski-Oja J, Kinnula VL, Oury TD, Koli K: Gremlinmediated decrease in bone morphogenetic protein signaling promotes pulmonary fibrosis. Am J Respir Crit Care Med 2008, 177:321-329

35. Kim M, Yoon S, Lee S, Ha SA, Kim HK, Kim JW, Chung J: Gremlin1 induces BMP-independent tumor cell proliferation, migration, and invasion. PLOS One 2012, 7:e35100 